\title{
Towards Increasing Feedbacks and Diffusion of Information in Social Networks
}

\author{
http://dx.doi.org/10.3991/ijes.v4i1.5477 \\ M. Kodad and E.M. Jaara \\ LARI, University Mohammed First, Oujda, Morocco.
}

\begin{abstract}
The purpose of this document is to highlight two strategies which increased feedbacks and stimulated the diffusion of information in social networks. Starting by an online survey, which assists searchers in understanding the behavior of social network users, to define the problem. The information received with this survey has been tested on validation by an analyze on the most popular type of posting on social networks. The results of this study provided two strategies as a solution for the problem of dissatisfaction among users of social networks and to increase feedbacks and diffusion of information on social network. One strategy is manual and is based on the type of publication and the second strategy is automatically and takes the concept of collaborative work in to account.
\end{abstract}

Index Terms - Social network, Feedbacks, Diffusion of information, Collaborative work.

\section{INTRODUCTION}

Nowadays, social networks, such as Facebook and Twitter are unthinkable. It was in the beginning of 2000 that communication made a huge transformation with social networks like Facebook and MYSPACE. Until now the biggest social network is without doubts Facebook.

The great increase of Subscribers at social networks is alarming. Facebook, for example, has for five years more than 14083 and more than 800 million users [1]. These numbers show to what extent social networks are implanted in our life style. Therefore the impact should be analyzed. Starting with the positive effect of these technologies.

Obviously, the use of social networks has several benefits, which are widely known. It is easy to use, inexpensive and it allows a quick exchange. Therefore it creates a possibility to reach thousands of people almost instantly. Furthermore, social networks engenders a lot of advantages for the emotional health of people, by making it possible to meet new friends and reconnect with old ones. It also provides a platform to share opinions and knowledge and help people.

Therefore, social networks remain an essential tool of communication, which quietly entered not only our daily life, but also the business field. That is why, social networks have a huge potential to be a tool for communication and collaboration within organizations.

"Alexa internet", the best known website that provides statistics on global web traffic of all websites [2], provided us with information to classify the top ten of most used websites of social networks. It will be the subject of future research. And according to this classification Facebook is the world leader of social networks, and this is the reason why this paper focuses on this social network.

In this document we will analyze some frequently asked questions and attempt to find answers to certain problems that social network's users, especially Facebook subscribers experience. A lot of questions can be formulated on this subject, but this study will focus on a couple of questions. The three main questions will be: 'Are owners of facebook pages satisfied with the interaction of fans?', 'Is the reach rate fixed or does it depend on the number of fans?' and 'Does the number of fans influence the reach rate?'.

We will also introduce an experiment, which will allow us to explain the difference between the reach rate of different types of posting and which can help us to determine the most effective type of posting on Facebook pages. This paper will also provide two strategies, a manual strategy and an automatic strategy, to gain insight on how to increase interaction on an online publication and how to expand its distribution. The manual strategy is based on four parameters: "Title", "Photo", "Identify" and "Fans motivation". The automatic strategy is based on collaborative working.

The rest of this paper is structured as followed. In section 2 the problems will be presented, section 3 will provide data analysis, section 4 presents "Methods, Application and Results", and this paper will end with Conclusion \& perspectives in the last section.

\section{PROBLEMS}

Several researches are conducted in the social networks field. Some of them have unveiled some problems, either theoretical or technical.

Facebook, which is the best visited social network in the world, offers three services : "pages", "profiles" and "Groups". Facebook can be updated by issuing publications, organizing events, and adding applications, etc. However, we can find contradictions in what is said and statements of Facebook itself, especially in their "Business Generating Results on Facebook". Facebook states that if you want your publications to be seen by fans, you have to pay.

Currently the companies seek to maximize the diffusion of publication. The latter is useful for companies for two main goals, the first is "win the trust of customers" and second is "make more money". In return customers seek for information disseminated by the company or by online services. Since social network is used almost everywhere and on different platforms, like 
mobile phones and tablets, it is accessible at all placed and all times

Figure 1 shows the business-customer relationship, it shows that a company should target customers interested in their products to achieve the formulated goals. This business-customer relationship requires us to pose some questions: Do publications reach users (in time)? Do they reach the targeted users? Do the types of publications have the same distribution strategy? Are facebook users satisfied with the interactions on their publications? How to increase interaction and expand the distribution? How to increase the reach rate? Is the reach rate fixed or does it depend on the number of fans? Does the number of fans influence the reach rate?

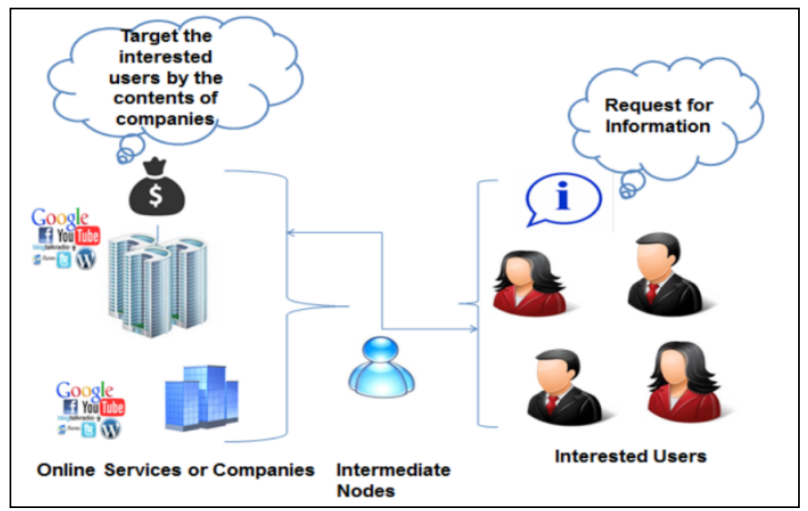

Figure.1. Business-Customer relationship

In relation with the subject of business-costumer relationship, and according to several researchers in the engineering field, a system is reliable when the probability to fulfill its mission in a period corresponds to that specified as required. If we implement this definition on an owner of a Facebook page, the reliability for them is to have a formulated satisfying rate of "Reach".

With its new strategy, Facebook allows the administrators of Facebook pages to view detailed statistics of each publication, including the reach.

The number of "Reach", requires us to ask some questions. For example: How can we measure the number of "Reach"? Is the number of "Reach" proportional to the type of publications (Photo, Link, Status)? And the type of interactions (Share, Like, Comment)? Or does it depend on the number of fans on a Facebook page?

\section{DATA ANALYSIS}

To find answers to the formulated questions ( see paragraph : " Problems" ), we had two strategies. On one hand we have launched a survey using "Google Doc", in order to receive what users think about social networks and especially users of Facebook. On the other hand, we conducted an experiment to measure the reliability of published content.

\section{A. Online Survey}

\section{1) Materials and Methods}

To analyze some problems, it was necessary to set up an online survey. We have put an open survey in a period from November 17, 2014 untill November 21, 2014, with "Google doc". The survey was open to people from different countries. The survey had 1000 respondents, mainly students. All respondents were required to have a Facebook account and should follow some Facebook pages as well.

Here are the elements of the technical file of the survey online:

- Organization Committee: LARI Laboratory

- Number of questions: 11 questions

- Number of interviewees: 1000 persons

- Nature of interviewees: persons from different countries, different ages.

- Tools: Google Doc

- $\quad$ Starting date: November 17th, 2014

- End date: November 21st, 2014

- Political sharing: on Facebook pages, with an email and on electronic journals.

- Requirements: All interviewees must have a Facebook account.

- $\quad$ Language used: French easy level.

- The questions are as follow:

1. Which type of post do you like to share?

2. Why do you share posts?

3. What do you expect from sharing them?

4. If your posts are not reliable, what do you do?

5. How do you feel when your posts get a lot of likes?

6. Do you click "like" on a post that you appreciate?

7. When you share a post, what type do you prefer?

8. Give a mark from 1 to 5 for each Facebook option.

9. Are you an owner of a Facebook page?

10. Are you satisfied with feedback from fans?

11. If you have 1000 fans, how much of "reach" is satisfying for you?

2) Results

Here are some results found through the survey.

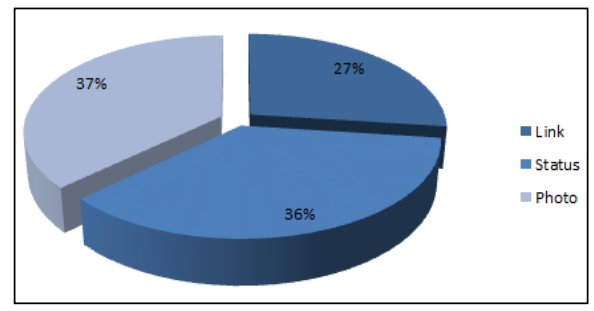

Figure. 2. The type of most shared publication

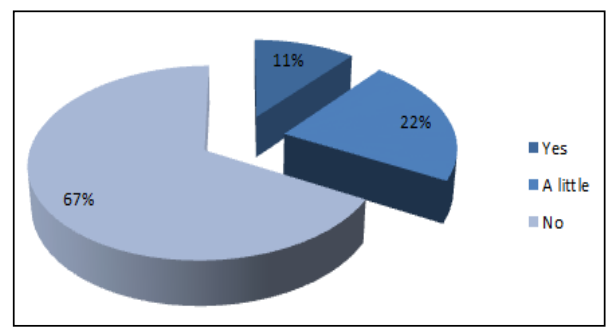

Figure. 3. Satisfaction fans interactions 
Figure 2 shows the result from question 1 of the survey. According to this result $27 \%$ of people share "Links", 37\% of people share a "Photo" and 36\% of people share a "Status".

Figure 3 shows the result of satisfaction of fans interactions asked in question 10 . These results show us that $67 \%$ of respondents are not satisfied with the interaction of their fans, $22 \%$ said "a little" and $11 \%$ persons say that they are satisfied. In this question we also asked for explanations for the following answers: "not satisfied" and "somewhat", to understand the reason for their lack of satisfaction. Here are the main answers: some experience too little interaction from their fans and they aspire more. Since there are fans who follow pages, but do not interact on the subjects.

Figure 4 shows the results found in Question 6. 731 participants (73\%) answered "yes", 71 participants (7\%) answered "no", and 198 participants (20\%) state that "it depends on his relationship with the owner of the page ".

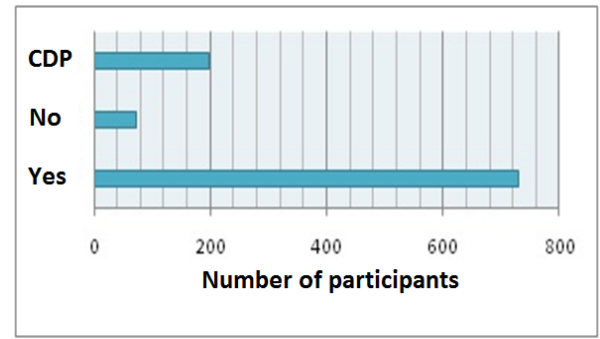

Figure. 4. Result of the question: do you click "like" on a post that you appreciate?

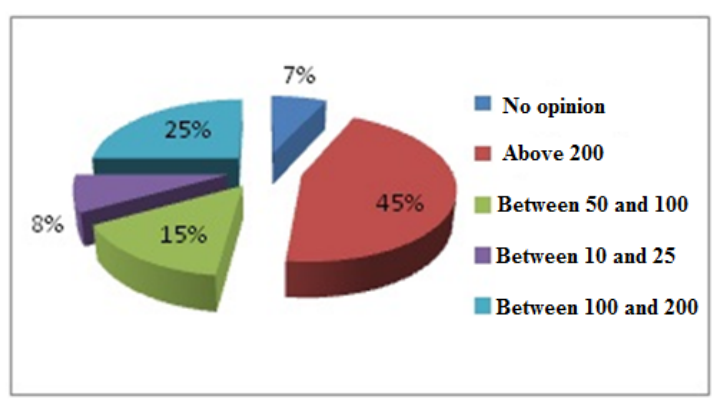

Figure. 5. Result of the question: If you have 1000 fans, how much of "reach" is satisfying for you?

Figure 5 shows the results from question 11 of the survey. 71 participants (7\%) answered "No opinion", 77 participants (8\%) answered "Between 10 and 25", 148 participants (15\%) say "Between 50 and 100", 253 participants which represents $25 \%$ of respondents answered with "Between 100 and 200" and 451 participants (45\%) say "above 200".

What we can deduce from the results found, is that there are two main problems: the number of interactions and the number of "reach".

\section{B. Experiments}

\section{1) Materials and Methods}

To answer the questions asked in the previous paragraph, we conducted a test, by publishing a single publication on different Facebook pages that we manage, for 24 hours using all three types of publications (links, photo and status). Figure 6 shows the six Facebook pages used and the number of fans of each page (example: BC2 page contains 42,784 fans).

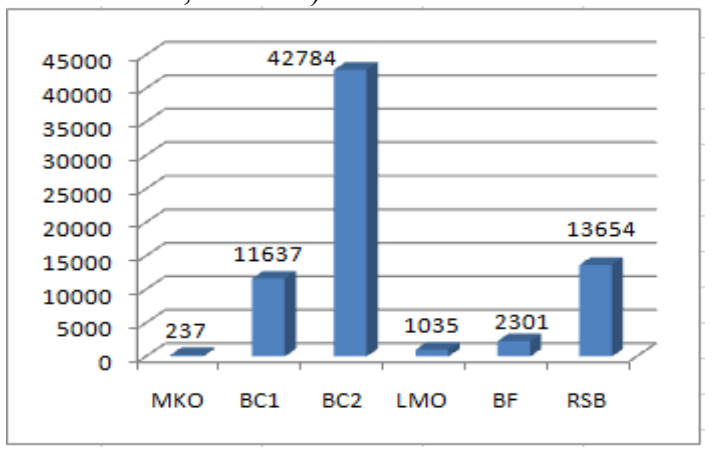

Figure.6. Number of fans of each Facebook page used in this experiment

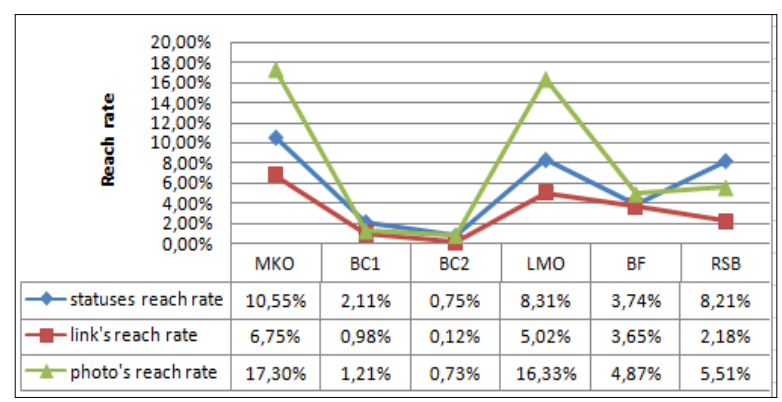

Figure.7. The reach rate for each type of post

It should be noted that the MKO, BC1, BC2, LMO, BF and $\mathrm{RSB}$ are the abbreviations for the page names that we manage.

2) Results

We started with case (1) "sharing a Status publication", then case (2) "sharing a Link publication" and we finished with case (3) "sharing a Photo publication". The tables (Table I, Table II and Table III) present the results collected after 24 hours of launching each publication.

\section{Case (1): Sharing Statuses}

TABLE I

RESULTS ANALYSIS OF « REACH » IN FACEBOOK PAGES SHARING A

\begin{tabular}{ccccccc}
\hline Page Name & MKO & BC1 & BC2 & LMO & BF & RSB \\
\hline $\begin{array}{c}\text { Number of } \\
\text { Fans }\end{array}$ & 237 & 11637 & 42784 & 1035 & 2301 & 13654 \\
\hline Likes & 0 & 1 & 5 & 0 & 2 & 45 \\
Comments & 0 & 0 & 3 & 2 & 1 & 20 \\
Shares & 0 & 0 & 0 & 0 & 0 & 1 \\
\hline Reach & 25 & 246 & 323 & 86 & 86 & 1121 \\
\hline Reach Rate & $10.55 \%$ & $2.11 \%$ & $0.75 \%$ & $8.31 \%$ & $3.74 \%$ & $8.21 \%$ \\
\hline
\end{tabular}

Case (2): Sharing Links

TABLE II

RESULTS ANALYSIS OF « REACH » IN FACEBOOK PAGES SHARING A LINK

\begin{tabular}{ccccccc}
\hline Page Name & MKO & BC1 & BC2 & LMO & BF & RSB \\
\hline $\begin{array}{c}\text { Number of } \\
\text { Fans }\end{array}$ & 237 & 11637 & 42784 & 1035 & 2301 & 13654 \\
\hline Likes & 0 & 1 & 0 & 1 & 0 & 10 \\
Comments & 0 & 0 & 0 & 1 & 2 & 2 \\
\hline
\end{tabular}


PAPER

TOWARDS INCREASING FEEDBACKS AND DIFFUSION OF INFORMATION IN SOCIAL NETWORKS

\begin{tabular}{ccccccc}
\hline Shares & 0 & 0 & 0 & 0 & 0 & 1 \\
\hline Reach & 16 & 114 & 53 & 52 & 84 & 298 \\
\hline Reach Rate & $6.75 \%$ & $0.98 \%$ & $0.12 \%$ & $5.02 \%$ & $3.65 \%$ & $2.18 \%$ \\
\hline
\end{tabular}

webmasters, created Facebook pages just to share links.

In this article, we propose two strategies, one manual and the other one automatic. they enable us to increase the interaction and extend the dissemination of information.

Case (3): Sharing Photos

TABLE III

RESULTS ANALYSIS OF « REACH » IN FACEBOOK PAGES SHARING PHOTOS

\begin{tabular}{lllllll}
\hline Page Name & MKO & BC1 & BC2 & LMO & BF & RSB \\
\hline $\begin{array}{l}\text { Number of } \\
\text { Fans }\end{array}$ & 237 & 11637 & 42784 & 1035 & 2301 & 13654 \\
\hline Likes & 5 & 7 & 22 & 18 & 5 & 102 \\
Comments & 1 & 1 & 6 & 1 & 1 & 13 \\
Shares & 0 & 0 & 0 & 0 & 0 & 1 \\
\hline Reach & 41 & 141 & 311 & 169 & 112 & 752 \\
\hline Reach Rate & $17.30 \%$ & $1.21 \%$ & $0.73 \%$ & $16.33 \%$ & $4.87 \%$ & $5.51 \%$ \\
\hline
\end{tabular}

NB: The reach rate is calculated according to this formula:

\section{Reach Rate $=$ Reach Number $/$ Number of Fans}

According to the results (see : Table I, Table II and Table III) that are summarized in figure 7 , some formulated questions can be answered. It also provides a lot of information and some facts, that were not known before, including:

- As long as the number of fans increases, the reach rate decreases.

- As long as the number of interactions increases, the reach rate increases.

- The reach rate of "Photo" publication type is the highest.

The reach rate of "Link" publication type is the lowest.

3) Satisfaction results

The comparison between the survey results and the experimentation results shows the following points:

- The result of question 11 of the survey shows us that $45 \%$ of respondents would like to have a number of reach "more than 200", 25\% want to have it "between 100 and 200 ". Therefore we can say that $70 \%$ of respondents want a number of reach bigger than 100 when it concerns a page of 1000 fans.

- In the experiment, we found that when a page has more than 1000 fans (case of "LMO" page with 1035 fans), the number of reach differs according to type of publication, by sharing a "Status" publication we found 86 "reach", 52 "reach" by sharing a "Link" publication, and we found 169 "reach" in case of sharing a "Photo" publication.

- If we compare the survey results with the results of the experiment, we can say that the "photo" publication responds well to the demands and needs of owners and managers of Facebook pages, unlike the "link" publication type which is a big challenge among owners of Facebook pages.

\section{Methods, ApplicAtion And RESUlts}

According to the results described in the previous paragraph, we can conclude that the publication type "Link" is the weakest of publications, in both the interactions and the reach rate. While several Facebook pages, especially those who own websites and

\section{A. Manual strategy}

\section{1) Methods}

The manual strategy that we propose is based on four parameters, "Photo", "Title", "Identify" and "Fans Motivation". First it is necessary to have true and correct publications on a page, so that the Facebook page can be used as a source of information and to make it more reliable for fans. However the "Photo" and "Title" are two important elements that can attract a lot of fans if they are presented in an attractive way, but it must be transmitted from the publication type "Link" to the publication type "Photo" to benefit from the parameter "Identify", that has become a necessary element to attract more people to the subjects (especially when we know that the subject interests them) and therefore probably have more interactions. Finally the last thing that is interesting and gives more reputation to a Facebook page is the "Fans Motivation".

Photo: The attractiveness of a picture plays a very important role in expanding the interaction of fans.

Title: A title must be presented in such a way that the fans want to "click", to "like" or "share" the publication. The author himself should be attracted to the title he presented.

Identify: Identify people to a publication; it is a request to people to react. This will easily increase interactions on your publications.

Fans motivation: It is important to respond to questions posed by your fans. It proves that you are listening to fans and you are receptive of their comments. A page must propose topics to discuss and organize competitions (Best photo) etc. to increase the interaction.

\section{2) Application \& results}

After implementation of a strategy as described above, we took the case of LMO page by transmitting a publication type "Link" to a publication type "Photo" and then we identified 30 people to this publication.

TABLE IV

RESULT OF FEEDBACKS SHARING A "PHOTO" IN LMO PAGE

\begin{tabular}{cc}
\hline Page Name & LMO \\
\hline Number of Fans & 1035 \\
\hline Likes & 36 \\
Comments & 17 \\
Shares & 2 \\
\hline Reach & 1865 \\
\hline Reach Rate & $180.19 \%$ \\
\hline
\end{tabular}

Table IV describes the results found after sharing a publication type "Photo" on the LMO page. As shown you can see the considerable value of reach rate that has increased significantly, reaching to $180.19 \%$ instead of $16,33 \%$ that we found previously (see Figure 7 ). Now the reach rate exceeds the number of fans of LMO page, and we can see the increase of interactions (36 likes, 17 comments, 2 shares instead of 18 likes, 1 comment and 0 shares), coming either from the fans of the page, people identified or friends of those identified. 


\section{B. Automatic strategy}

Our second contribution is the establishment of a system to increase any kind of feedback and interaction between users in social networks, using the notion and the concept of collaborative work in a reliable, credible and transparent way. Thus, the notion of collaborative work today means a work that is no longer based on the traditional hierarchical organization, and more specifically a new work methode (possibly integrated into an economic production model), where many people work together through the information and communications technology [3]. It is based on a logical communication facilitated by the internet [4] or of mutual interest. In the software field, it has for example accelerated and improved efficiency many tools [5], in the thanks part to the "passage of the Copyright Copyleft" [6].

In the governance, various studies have concluded that some collaborative tools or collaborative approaches could enhance participative democracy, "adaptive approaches" and even allow new forms of socioecosystem resilience [7] via an "adaptative comanagement" companies [8] and their environment; particularly in light of ecological and climatic context changeable [9], uncertain or restored [10] or with natural resources (overfishing [11], deforestation, erosion and soil degradation, etc.) possibly by drawing on local and ancestral knowledge [12]. Adaptive and collaborative comanagement is one of the solutions [13] proposed for efficient management of biodiversity.

\section{1) Architecture}

Figure 8 shows the architecture of the system that we have entitled S2AF, which is based on n-tier architecture. Orientation to this architecture was driven by several aspects. Indeed, in such a system, many subscribers can access to the database which made it vulnerable, with a multi-tier architecture. The database access is performed only by the application server. It is possible to manage security at the application server, for example by maintaining a list of users with their passwords and their rights of access to system functions without changing the overall structure.

Interface Level: At this level, the S2AF system provides communication between the user and the machine with a simple graphical interface. It is the main access to our system. The interface is divided into two windows, one for the monitoring and management of publications supplied by the user himself, and the second to deal with interactions on publications put by others in a collaborative spirit.

Execution Level: At this level, the system executes the requests of all interaction flow by retrieving the identifier of the user and give him a " +1 " if the operation is successful, if not " 0 ". For the receptors interaction, we remove "-1" from his score once receiving an interaction as shown in Figure 11. The queries executed by S2AF are saved in the database with all information of the users and the interactions made, taken the calculation of indicators in consideration.
Data Level: In this level, the system is responsible for the collection of data using intermediate tools, for Facebook we use "Facebook App". In this level the construction of the database is made, the data of interactions is collected, and the injection of these data in the database of our system is defined in a pattern. The wildcard S2AF imposes a choice of data common to the most social networks.

Study Level: At this level, the system shows the welldefined schemas as diagrams and curves, and the calculation results of the indicators whether those of satisfaction or those of content. S2AF also presents the content and the process of activity done by users.

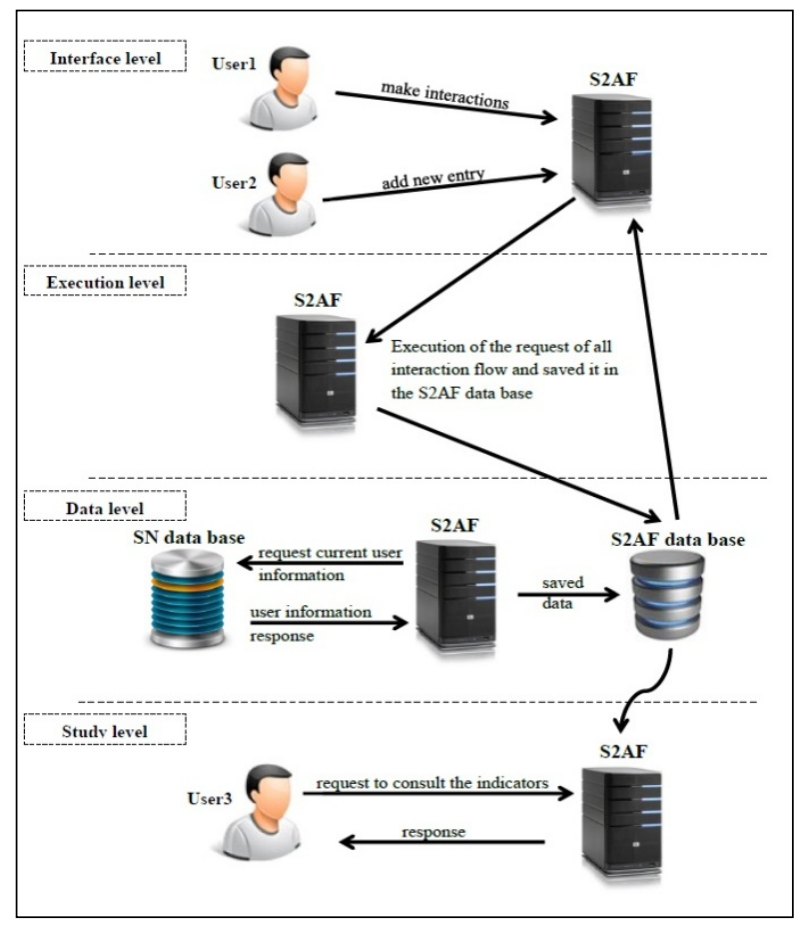

Figure.8. The architecture of S2AF System

\section{2) Objectives and functioning}

The indicators calculated by our system are divided into three categories: Indicators of the content of publications, Satisfaction indicators and Indicators of Feedback Performance. The data extracted by S2AF for the calculations of indicators are those related to the identified user (identifier, name, email address...), its interactions (like, share, comment...) and its publications (image, link, status).

Indicators of the Content of Publications: Indicators of the content of publications indicate information on the types of publications and social network use. These indicators concern users interactions related to the task and content of the activity performed.

Satisfaction Indicators: These indicators refer to satisfaction with interactions and collaborations realized. The indicators having a high value interpretation, provide a state of satisfaction regarding the achievement of objectives, by calculating the degree of user presence on $\mathrm{S} 2 \mathrm{AF}$ and whether the user is transmitter or receiver. 
Indicators of Feedback Performance: These indicators refer to the modes or the quality of feedback and collaboration. Among the indicators having a high value interpretation, we can note those who realize the quality of collaboration during interactions and those who provide the state of relations established between users.

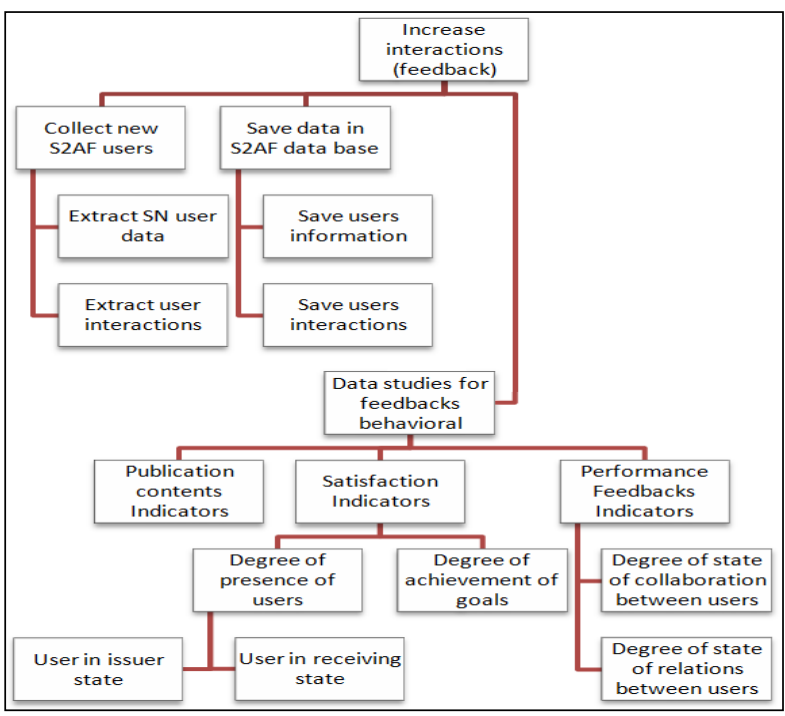

Figure.9. Hierarchical diagram of S2AF Goals

Regarding the choice of indicators calculated by our S2AF system, we have adopted an incremental approach; we started by determining some indicators in order to test the architecture of our system, and as necessary we can incorporate other indicators that stakeholders (user, administrator, webmaster,...) consider relevant. Figure 9, shows the hierarchical diagram of the goals of our system and integrated indicators.

For the development and specification of our S2AF we used the process 2TUP (2 Tracks Unified Process), it belongs to the category of processes that meets the characteristics of the unified process. The 2TUP process provides a response to continual change constraints on information systems. In this sense, it strengthens the control over the evolution and correction capabilities of such systems.

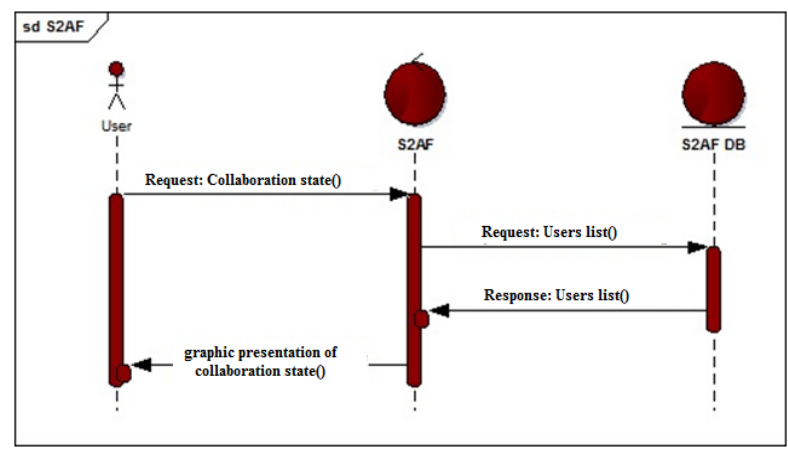

Figure. 10. Sequence Diagram providing the indicators of Feedback performance: the state of collaboration between users
We have defined several "use case", according to the tasks that the system is required to perform. We present (see Figure 10 : "state of collaboration between users") an example sequence diagram relating to the "use case" of the indicator of feedback performance. This "use case" describes the process executed by the system to receive the information concerning the feedback performance and especially the state of collaboration between the S2AF users.

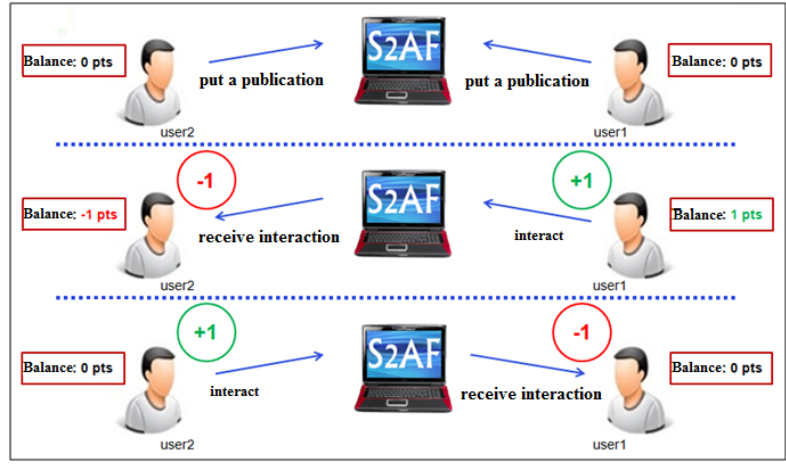

Figure.11. Functioning of S2AF system

The request is initiated by the user of S2AF system; it launches a new request to access the database in order to return a list of users who interact on publications posted by other users. The result is returned to the system that performs the graphic presentation of the indicator as a tree.

Figure 11 shows the operation of the system; for the case of two users logged on the system, delivering their first contact with the S2AF interface, they must connect and subsequently either seek to post a publication or to interact with publications mailed by others. The balance of each user will be incremented by " 1 " point when it interacts with a publication and will be decremented by " 1 " point when it receives interaction. But it remains to note that the constraints is that the publication of a user with a "-1" balance never are displayed to others.

\section{3) Application \& results}

In order to test the performance of our system we found it necessary to create a community based in the social network Facebook. This community has 5 real users (Hassan, Sami, Driss, Farid and Kamal), see Figure 12.

The relationship of this community is as follow: Hassan has 4 known friends (Sami, Driss, Farid and Kamal), Sami has 3 known friends (Driss, Hassan and Farid), Driss has two known friends (Sami and Hassan), Farid has two known friends (Sami and Hassan) and Kamal has one known friend (Hassan). 


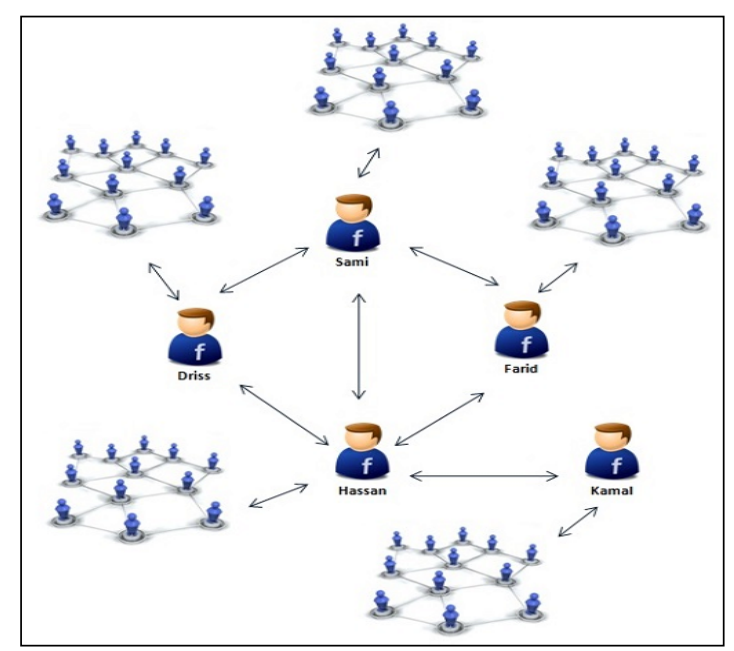

Figure.12. Example of a real social network on Facebook with 5 real users

Before or after using S2AF: how many interacted people overlook a publication?

To do this, we executed the following cases:

- Case 1: Hassan, Sami, Driss, Farid and Kamal share a publication as "image" type.

- Case 2: Hassan, Sami, Driss, Farid and Kamal share a publication as "status" type.

- Case 3: Hassan, Sami, Driss, Farid and Kamal share a publication as "link" type.

Results « Before using S2AF »:

The following tables (see Table V, Table VI and Table VII) describe the interactions made between the actual users of social network Facebook (Hassan Sami, Farid, and Kamal Driss). The information in these shares is collected after 24 hours of the launch of the publication by these users.

Case 1: Sharing a publication as "image" type. As described in the previous table (see Table V), when Hassan shared a publication, he had some interactions (from Sami, Driss and Kamal). Sami and Driss had one interaction (from Hassan). Farid had one interaction (from Sami). Finally Kamal has received no interaction to his publication. So the total of interactions is 6 on 12 , which means $50 \%$ of the expected interactions.

TABLE V

RESULTS OF SHARING A « PHOTO » PUBLICATION BEFORE USING S2AF

\begin{tabular}{lccccc}
\hline Emet/Réce & Hassan & Sami & Farid & Driss & Kamal \\
\hline Hassan & - & 1 & 0 & 1 & 1 \\
\hline Sami & 1 & - & 0 & 0 & N/A \\
\hline Farid & 0 & 1 & - & N/A & N/A \\
\hline Driss & 1 & 0 & N/A & - & N/A \\
\hline Kamal & 0 & N/A & N/A & N/A & - \\
\hline
\end{tabular}

Case 2: Sharing a publication as "status" type. As described in Table VI, When Hassan shared a publication, he has some interactions from Sami and Kama), Sami and Driss had both one interaction from Hassan, Farid has one interaction from Sami and Kamal has no interaction his publication. So the total of interactions is 5 on 12 , which means $41.67 \%$ of the expected interactions.

TABLE VI

RESULTS OF SHARING A « STATUS » PUBLICATION BEFORE USING S2AF

\begin{tabular}{cccccc}
\hline Emet/Réce & Hassan & Sami & Farid & Driss & Kamal \\
\hline Hassan & - & 1 & 0 & 0 & 1 \\
\hline Sami & 1 & - & 0 & 0 & N/A \\
\hline Farid & 0 & 1 & - & N/A & N/A \\
\hline Driss & 1 & 0 & N/A & - & N/A \\
\hline Kamal & 0 & N/A & N/A & N/A & - \\
\hline
\end{tabular}

Case 3: Sharing a publication as "link" type. As described in Table VII, When Hassan shared a publication, he got one interaction from Farid. Sami and Kamal received no interaction, Farid and Driss had one interaction from respectively Sami and Hassan. So the total of interaction is 3 on 12 , which means only $25 \%$ of the expected interactions.

TABLE VII

RESULTS OF SHARING A « LINK » PUBLICATION BEFORE USING S2AF

\begin{tabular}{|c|c|c|c|c|c|}
\hline Emet/Réce & Hassan & Sami & Farid & Driss & Kamal \\
\hline Hassan & - & 0 & 1 & 0 & 0 \\
\hline Sami & 0 & - & 0 & 0 & N/A \\
\hline Farid & 0 & 1 & - & $\mathrm{N} / \mathrm{A}$ & N/A \\
\hline Driss & 1 & 0 & N/A & - & N/A \\
\hline Kamal & 0 & N/A & N/A & $\mathrm{N} / \mathrm{A}$ & - \\
\hline
\end{tabular}

Legend :

Emt : Transmitter

Réce : Receiver

N/A : Not Applicable.

\section{Results « After using S2AF »}

The same case was redone with the same three cases; but this time with the user of our S2AF system and it gave the following results:

Case 1: Sharing a publication as "image" type, as described in Table VIII. When Hassan shared a publication, he had some interactions from his friends (Sami Farid, Driss and Kamal), the same happend for the others users. So the total of interactions is 12 on 12 , which mean $100 \%$ of the expected interactions.

TABLE VIII

\begin{tabular}{cccccc} 
RESULTS OF SHARING A « PHOTO $»$ PUBLICATION AFTER USING S2AF \\
\hline Emet/Réce & Hassan & Sami & Farid & Driss & Kamal \\
\hline Hassan & - & 1 & 1 & 1 & 1 \\
\hline Sami & 1 & - & 1 & 1 & N/A \\
\hline Farid & 1 & 1 & - & N/A & N/A \\
\hline Driss & 1 & 1 & N/A & - & N/A \\
\hline Kamal & 1 & N/A & N/A & N/A & - \\
\hline & & & & &
\end{tabular}

Case 2: Sharing a publication as "status" type, as described in Table IX. When Hassan shared a publication he had some interactions from his friends (Sami Farid, Driss and Kamal), the same happened for the other users. So the total of interactions is 12 on 12 , which mean $100 \%$ of the expected interactions. 
TABLE IX

RESUlTS OF SHARING A «STATUS » PUBLICATION AFTER USING S2AF

\begin{tabular}{cccccc}
\hline Emet/Réce & Hassan & Sami & Farid & Driss & Kamal \\
\hline Hassan & - & 1 & 1 & 1 & 1 \\
\hline Sami & 1 & - & 1 & 1 & N/A \\
\hline Farid & 1 & 1 & - & N/A & N/A \\
\hline Driss & 1 & 1 & N/A & - & N/A \\
\hline Kamal & 1 & N/A & N/A & N/A & - \\
\hline
\end{tabular}

Case 3: Sharing a publication as "link" type, as described in Table X. When Hassan shared a publication he had some interactions from his friends (Sami Farid, Driss and Kamal), the same happened for the other users. So the total of interactions is 12 on 12 , which mean $100 \%$ of the expected interactions.

TABLE $\mathrm{X}$

RESULTS OF SHARING A « LINK » PUBLICATION AFTER USING S2AF

\begin{tabular}{cccccc}
\hline Emet/Réce & Hassan & Sami & Farid & Driss & Kamal \\
\hline Hassan & - & 1 & 1 & 1 & 1 \\
\hline Sami & 1 & - & 1 & 1 & N/A \\
\hline Farid & 1 & 1 & - & N/A & N/A \\
\hline Driss & 1 & 1 & N/A & - & N/A \\
\hline Kamal & 1 & N/A & N/A & N/A & - \\
\hline
\end{tabular}

Comparative table of results: Table XI, represents a comparative table of the found results. As you see, our S2AF method participates in a reliable way to increase interaction toward publications in social networks. The goal without the use of S2AF will not be achieved, but by using S2AF system we can achieve a result $100 \%$.

TABLE XI

COMPARATIVE TABle OF RESUlts "BEFORE" AND "AFTER" S2AF

\begin{tabular}{ccc}
\hline Publication $/$ method & Before S $2 \mathrm{AF}$ & After S2AF \\
\hline Photo & $50 \%$ & $\mathbf{1 0 0 \%}$ \\
\hline Status & $41,67 \%$ & $\mathbf{1 0 0 \%}$ \\
\hline Link & $25 \%$ & $\mathbf{1 0 0 \%}$ \\
\hline Average & $38,89 \%$ & $\mathbf{1 0 0 \%}$
\end{tabular}

\section{COnClusion \& Perspectives}

We saw the different types of publication, we also determined the most popular type of publication among Facebook users, with the survey we developed. Through the experiment we determined the most efficient type of publication. While highlighting the dissatisfaction of the owners of Facebook pages with the interactions of fans' and the reach rate, we proposed a strategy and method that help to increase interactions and thus reach rate.

In this document, we also showed our S2AF system whose aim is to help users of social networks to increase the feedbacks in a collaborative work. We have shown the S2AF scheme and the indicators that can be calculated. The results that are generated, are shown in a detailed way.

Regarding our perspectives, we expect to realize a case study for a large community, through the development of a multi-agent system. This system will help us generate users in an automatic way, aiming to achieve this goal and validate the conformity of our system in case of correction and progress.

\section{REFERENCES}

[1] C. MENLO PARK. Facebook Reports Fourth Quarter and Ful 1 Year 2014 Results. disponible ici : http ://investor.fb.com, 2015.

[2] L. Vaughan and R. Yang. Web traffic and organization performance measures: Relationships and data sources examined. Journal of Informetrics, $7: 699,2013$. http://dx.doi.org/10.1016/ j.joi.2013.04.005

[3] Grassineau B. L'exemple des logiciels libres et du projet d'encyclopédie libre et ouverte Wikipédia (Doctoral dissertation, Université Paris Dauphine Paris IX). La dynamique des réseaux coopératifs, 2009.

[4] Genthon G. and Phan D et coopération dans internet : une nouvelle organisation économique ? International Journal of Innovative Research in Advanced Engineering, Editions l'Harmattan :95, 1999.

[5] Horn F. L'importance du logiciel libre dans l'amélioration de l'efficience du logiciel. International Journal of Innovative Research in Advanced Engineering, Editions l'Harmattan :117, 1999.

[6] Zimmerman J.B. Logiciel et propriété intellectuelle : du copyright au copyleft. International Journal of Innovative Research in Advanced Engineering, Editions l'Harmattan :151, 1999.

[7] Berkes, F., J. Colding, and C. Folke. Navigating social-ecological systems : building resilience for complexity and change. Cambridge University Press, Cambridge, UK, 2003.

[8] F. Berkes and C. F. (eds.). Linking social and ecological systems : Management practices and social mechanisms for building resilience. Cambridge University Press, Cambridge, UK, 1998.

[9] F. Berkes and D. Jolly. Adapting to climate change : socialecological resilience in a canadian western arctic community. Conservation Ecology, 2 :18, 2001.

[10] Per Olsson, Carl Folke and Fikret Berkes. Research adaptive comanagement for building resilience in social-ecological systems. Environmental Management, 34 :75, 2001.

[11] Berkes, F. Co-management and the James Bay Agreement E Pinkerton. Co-operative management of local fisheries. University of British Columbia Press Vancouver. Canada 189 208, 1989.

[12] Berkes, F., and C. Folke. Back to the future : ecosystem dynamics and local knowledge. L. H. Gunderson C. S. Hol ling Panarchy : Understanding transformations in human and natural systems. Island Press Washington, DC 121 146, 2002.

[13] Buck, L. E., C. C. Geisler, J. Schelhas, and E. Wollenberg. Biological diversity : Balancing interests through adaptive col laborative management. CRC Press, New York, 2001.. http://dx.doi.org/10.1201/9781420042597

\section{AUTHORS}

M. Kodad is with the University Mohammed First, Oujda 60000 MOROCCO (mohcine.kodad@gmail.com). Mohcine KODAD is pursuing his Ph.D at University Mohammed the First in the Faculty of Sciences. He received his Master in Software Quality, from faculty of sciences at Ibn Tofail University in Morocco. His research activities at the LARI Laboratory (Computer Sciences Research) are focused on Feedbacks and diffusion of information in social networks.

E. M. Jaara, was with University Mohammed Fisrt, Oujda, 60000, MOROCCO (emjaara@yahoo.fr). El Miloud JAARA teaches the concept of Information System at University Mohammed the First in Morocco. He got his national doctorate in 2000 . He is the director of LARI Laboratory (in Computer Sciences Research) focusing on social networks, neural networks, genetic algorithms, image processing and parallelism.

Submitted 17 January 2016. Published as resubmitted by the authors 25 February 2016. 